\title{
TSH receptor mutation V509A causes familial hyperthyroidism by release of interhelical constraints between transmembrane helices TMH3 and TMH5
}

\author{
Beate Karges*, Gerd Krause ${ }^{\text {* }}$, Janos Homoki, Klaus-Michael \\ Debatin, Nicolas de Roux ${ }^{2}$ and Wolfram Karges ${ }^{3}$ \\ Pediatric Endocrinology, University Children's Hospital, University of Ulm, Prittwitzstrasse 43, D-89075 Ulm, Germany \\ ${ }^{1}$ Institute of Molecular Pharmacology, 13125 Berlin, Germany \\ ${ }^{2}$ INSERM U584, Hôpital Necker, 75006 Paris, France \\ ${ }^{3}$ Division of Endocrinology, Department of Internal Medicine, University of Ulm, 89081 Ulm, Germany \\ (Requests for offprints should be addressed to B Karges; Email: beate.karges@medizin.uni-ulm.de) \\ *(B Karges and G Krause contributed equally to this work)
}

\begin{abstract}
Mutations of the human thyrotrophin receptor (TSH-R) are a cause of thyroid adenomas and hyperthyroidism. Here we study mechanisms of receptor activation in a genomic TSH-R variant V509A located in transmembrane helix (TMH) 3, which we identify in a family with congenital hyperthyroidism, multiple adenomas and follicular thyroid cancer. Using molecular modelling and dynamic simulation, we predicted the release of amino acid residue A593 (located opposite in domain TMH5) from a tight 'knob-and-hole' interaction with TMH3, physiologically constrained in the native receptor state by the bulky side chain of V509. To experimentally validate this concept, we generated mutant TSH-R expression constructs for functional in vitro studies. TSH-R mutant
\end{abstract}

V509A showed a 2.8-fold increase in basal cAMP production, confirming constitutive TSH-R activation. The addition of a second site suppressor mutant A593V to TSH-R V509A resulted in the normalization of basal cAMP release, and the dose-responsiveness to TSH ligand was maintained. These data thus demonstrate that TSH-R V509A activation is caused by the release of TMH3TMH5 interhelical constraints, while the native TSH-R conformation is re-stabilized by the introduction of a spacious valine residue at position 593. In conclusion, we delineate a novel mechanism of constitutive TSH-R activation, leading to thyroid hyperfunction and neoplasia. Journal of Endocrinology (2005) 186, 377-385

\section{Introduction}

The thyrotrophin receptor (TSH-R) belongs to the family of $G$ protein-coupled receptors (GPCRs) containing seven transmembrane helices (TMH). Since 1994, activating germline mutations of the TSH-R have been identified as a cause of familial non-autoimmune thyrotoxicosis (Duprez et al. 1994). Persistent hyperthyroidism in affected individuals is often resistant to conventional treatment, eventually requiring complete thyroidectomy or ablative radiotherapy (Corvilain et al. 2001). Similarly, activating somatic mutations of the TSH-R have been found in toxic thyroid adenomas. There is evidence that constitutively active TSH-R variants are involved in thyroid cell growth and tumour development (Parma et al. 1993, Russo et al. 1995b, 1997, Spambalg et al. 1996, Fournes et al. 1998, Ludgate et al. 1999).

Activation of GPCRs is a dynamic process involving the release of inactive state constraints and sequential agonist-induced conformational changes until the active receptor state is reached (Schoneberg et al. 1999, Gether 2000, Schulz et al. 2000). Ligand-induced TSH-R activation mainly results in stimulation of adenylate cyclase with an increase in intracellular cyclic AMP (cAMP). Similarly, constitutively active TSH-R variants exhibit increased basal adenylate cyclase activity compared with the wild-type TSH-R (Corvilain et al. 2001). Natural activating TSH-R variants are thought to mimic the active conformation of the wild-type TSH-R and may spontaneously adopt a conformation able to activate $G$ protein-dependent signalling pathways (Parnot et al. 2002). However, the precise molecular mechanisms of TSH-R activation are not completely understood.

We here identify a German family with congenital hyperthyroidism, multiple adenomas and follicular thyroid cancer, associated with TSH-R genomic variant V509A. In this first described TSH-R germ line mutation (Duprez et al. 1994), we use molecular modelling and dynamic 


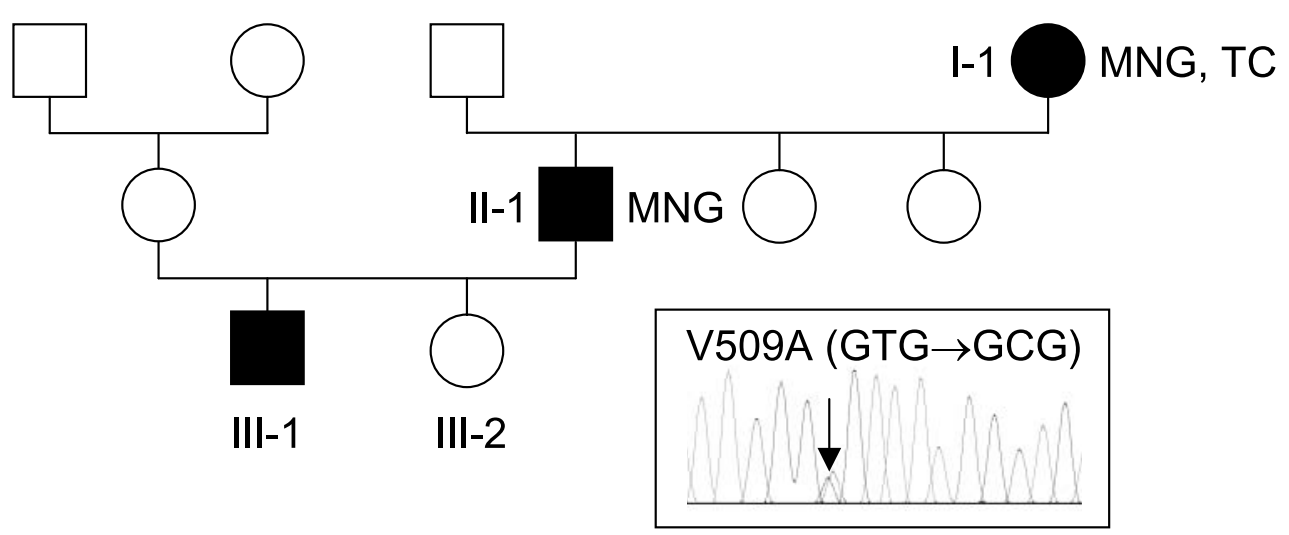

Figure 1 Family with non-autoimmune hyperthyroidism due to activating TSH-R mutation V509A. Closed symbols indicate patients with hyperthyroidism and heterozygous TSH-R mutation. Open symbols indicate healthy subjects. MNG, multinodular goitre; TC, follicular thyroid carcinoma. Insert: genomic TSH-R mutation V509A, located in exon 10.

simulation to predict the structure and function of the variant TSH-R protein. Site-directed mutagenesis and functional in vitro studies further indicate that the release of residue A593 in TMH5 from the steric knob-andhole' interaction with TMH3 is a pivotal element for constitutive TSH-R activation observed in this kindred.

\section{Subjects and Methods}

\section{Patient characteristics and laboratory evaluation}

The index patient (subject III-1, Fig. 1) is a boy of Caucasian origin who at the age of four years presented with hyperactivity and insomnia starting at the age of 6 months. His height was $121.8 \mathrm{~cm}$ (97th percentile), his weight was $22 \cdot 5 \mathrm{~kg}$ (90-97th percentile), his heart rate was $90 / \mathrm{min}$ and his blood pressure was $129 / 62 \mathrm{mmHg}$. Elevated thyroxine $(182.75 \mathrm{nmol} / 1$, normal range 61.4 $117 \cdot 2 \mathrm{nmol} / \mathrm{l})$, triiodothyronine $(3.6 \mathrm{nmol} / 1$, normal range $1 \cdot 83-3.30 \mathrm{nmol} / \mathrm{l}$ ) and low thyrotrophin (TSH) (0.03 mU/1, normal range $0.5-5.5 \mathrm{mU} / \mathrm{l})$ were detected, using commercial immunometric reagent kits (Vitros, Ortho-Clinical Diagnostics, Amersham, Bucks, UK). TSH receptor antibodies (TRAKhuman, Brahms Diagnostica, Henningstedt, Germany), thyroglobulin antibodies (VeliSa, Vita Diagnostica, Freiburg, Germany), and thyroid peroxidase antibodies (VeliSa, Vita Diagnostica) were negative. Thyroid volume, as determined by ultrasound, was increased to $4.4 \mathrm{ml}$ (>99th percentile compared with age- and gender-specific controls (Liesenkotter et al. 1997)), and the bone age was accelerated to $5 \cdot 5$ years.

The patient's father (subject II-1, Fig. 1) had suffered from clinical signs of hyperthyroidism since childhood, but diagnosis and antithyroid treatment was not established until 18 years of age. He underwent thyroidectomy for multinodular goitre at the age of 36 years. The mother and sister (subject III-2) of the index patient were healthy. His paternal grandmother (subject I-1) had undergone thyroidectomy because of hyperthyroidism and multinodular goitre at the age of 60 years. After the diagnosis of follicular thyroid cancer had been established by histopathology, she received ablative radioiodine therapy, and her further clinical course was uneventful. Informed consent was obtained for all analyses from patients or their parents, and studies were performed in accordance with the Declaration of Helsinki.

\section{TSH-R sequence analysis}

Sequence analysis of the human TSH-R gene (GenBank accession M31774) in patients was performed as described (Duprez et al. 1994) using genomic DNA from peripheral blood lymphocytes (DNeasy kit, Qiagen, Hilden, Germany) as template. Identical primers were used for genomic polymerase chain reaction and automated DNA sequencing (ABI Prism 7700, Applied Biosystems, Foster City, CA, USA).

\section{TSH-R expression constructs}

Wild-type TSH-R complementary DNA containing the entire coding sequence (2295 bp, kind gift of Dr Loos, Ulm, Germany) was cloned into the BamHI and EcoRI sites of pIRES (Clontech, Palo Alto, CA, USA). TSH-R plasmid constructs containing mutations V509A and A593V were generated by site-specific PCR mutagenesis (QuikChange, Stratagene, La Jolla, CA, USA), using wild-type TSH-R and TSH-R V509A plasmids as amplification templates respectively. All constructs were confirmed by bi-directional sequencing.

\section{Cell culture and in vitro transfection}

Signal transduction studies were performed in human embryonic kidney cells (HEK) 293 cells, grown in 


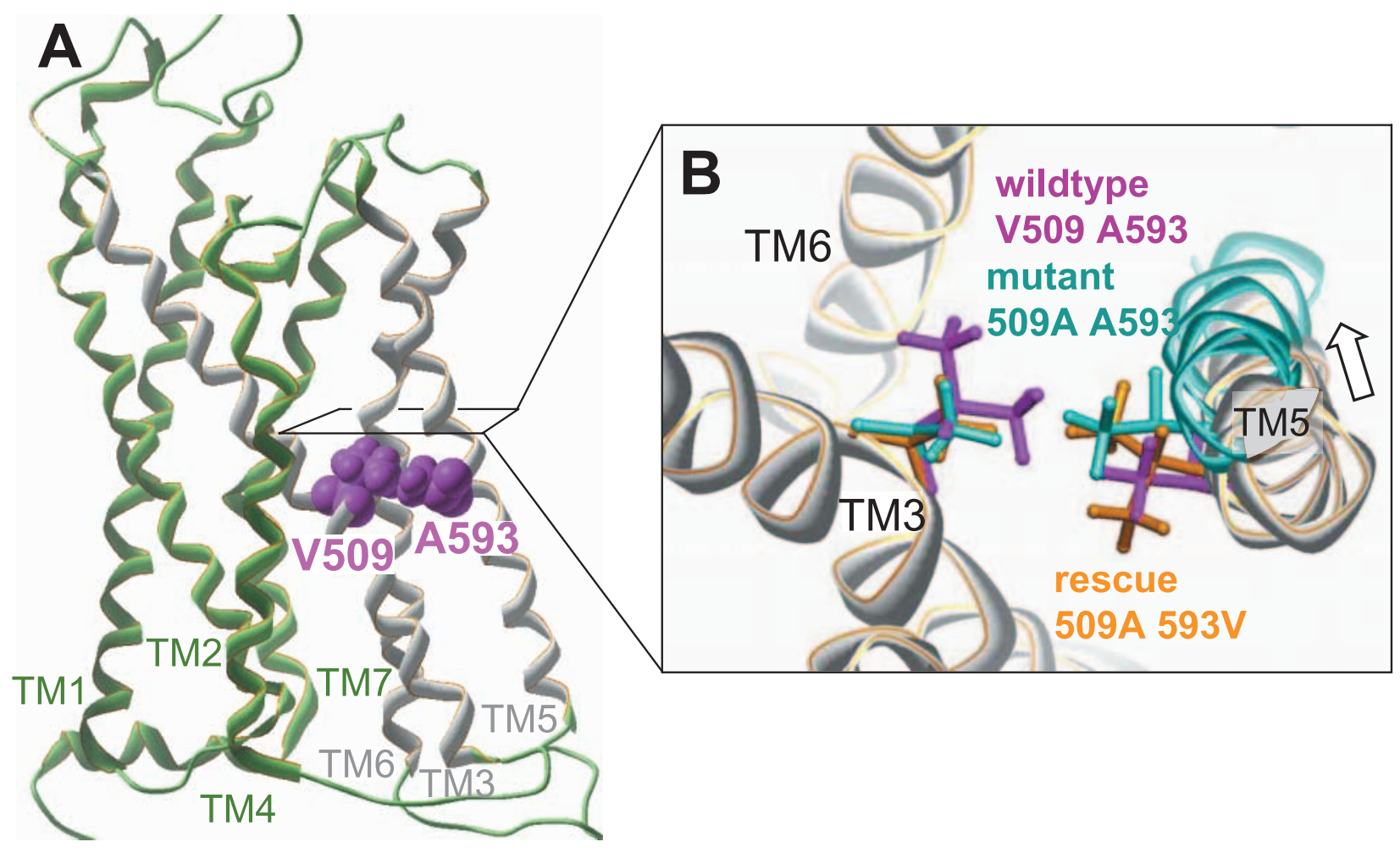

Figure 2 (A) Three-dimensional model of TSH-R transmembrane (TM) helices. Space-filled representation of side chains demonstrates the tight intertwined interactions between V509 (TMH3) and A593 (TMH5). (B) Detailed extracellular view of TMH3 (TM3) and TMH5 (TM5). Superposition of conformation frames from molecular dynamics for wild-type TSH-R (magenta), mutant V509A (cyan) and second-site mutant V509A/A593V (orange). The constitutive active mutant (cyan) allows closer distance between positions 509 (TMH3) and 593 (TMH5), with subsequent conformational change of TMH5 (arrow). The functional 'rescue' mutant (orange) reconstitutes a distance similar to wild-type TSH-R.

DMEM $/ 10 \%$ FCS $/ 1 \%$ penicillin-streptomycin. Cells $\left(1 \times 10^{5} /\right.$ well $)$ were seeded in 12 -well dishes previously coated with fibronectin (50 ng/ml; Sigma, St Louis, MO, USA). Transient transfection with TSH-R constructs $(1 \mu \mathrm{g}$ plasmid/well) was performed $24 \mathrm{~h}$ after plating (FUGENE6, Roche, Mannheim, Germany). Transfections were performed in triplicate, and each independent experiment was performed at least twice. TSH-R expression in cell lysates was studied by Western blotting using mouse monoclonal anti-TSH-R antibody (3H10, Brahms Diagnostica, Berlin, Germany) and the ECL system (Amersham, Freiburg, Germany). In addition, TSH-R cell surface expression was analysed by immunofluorescence microscopy (Olympus IX71) in transiently transfected HEK 293 cells using a monoclonal antibody directed against the extracellular part of the TSH-R (T5-34 antibody, 1:2000) and a FITC-conjugated secondary antibody (Alexa488, Molecular Probe, Eugene, CA, USA) as described (de Roux et al. 1996b).

\section{cAMP assay}

The accumulation of cyclic adenosine monophosphates (cAMP) in HEK 293 cells transfected with different
TSH-R constructs was measured to determine basal and stimulated receptor activity. Twenty-four hours after transfection, culture medium was replaced for $60 \mathrm{~min}$ by DMEM containing $0.4 \mathrm{mM}$ 3-isobutylmethylxanthine (Sigma). Subsequently, cells were lysed with $1 \mathrm{M}$ perchloric acid at $4{ }^{\circ} \mathrm{C}$, and cAMP accumulation in the culture medium was measured by radioimmunoassay (cAMP $\left[{ }^{125} \mathrm{I}\right]$ Biotrak assay system, Amersham, Germany). In a second set of experiments, dose-response relations of cAMP production were established by incubation of transfected cells in the presence of $0 \cdot 1,1$, and $10 \mathrm{mU} / \mathrm{ml}$ bovine TSH (Sigma). cAMP production ( $\mathrm{pmol} / \mathrm{well}$ ) is shown as the mean \pm S.D of triplicate measurements, and all experiments were performed at least twice, with identical results.

\section{Molecular modelling of TSH-R structure}

The construction of the TSH-R model has been described previously (Neumann et al. 2001). The starting structure of the transmembrane helices of the human TSH-R was based on the crystal structure of bovine rhodopsin as template (Palczewski et al. 2000). The TSH-R structure model was computed with particular emphasis on the 
transmembrane helices, without the large amino-terminal domain but including extra- and intracellular loops. All model components were assembled with the biopolymer module of the Sybyl program package (TRIPOS Inc., St Louis, MO, USA). Molecular dynamic simulations were performed at $300 \mathrm{~K}$ for $1 \mathrm{~ns}$ using the AMBER $6 \cdot 0$ force field (Case et al. 1998), where only hydrogen bonds of the TMH backbones maintaining the $\mathrm{TMH}$ helices were restrained.

\section{Results}

\section{Familial hyperthyroidism and thyroid neoplasia}

In the index patient (Fig. 1, individual III-1), mild hyperthyroidism was diagnosed at the age of four years, when antithyroid treatment was initiated. During his subsequent clinical course, carbimazole doses were adjusted to maintain thyroxine in the upper normal range, without signs or symptoms of hyperthyroidism. Medical treatment was well tolerated. At the age of 11 years and 6 months, ultrasound revealed an increased thyroid volume ( $8.5 \mathrm{ml}$, corresponding to $>97$ th percentile of age- and gender-specific controls (Liesenkotter et al. 1997)) without evidence of thyroid nodules. During follow-up, his longitudinal height and weight were above the 97th percentile (Prader et al. 1989) with a height of $178 \mathrm{~cm}$, weight of $84.4 \mathrm{~kg}$, and body mass index of $27 \cdot 2 \mathrm{~kg} / \mathrm{m}^{2}$ at the age of 12 years. His bone age was accelerated to 16 years. The predicted adult height is $181.6 \mathrm{~cm}$ compared with midparental target height of $176.8 \mathrm{~cm}$.

His father (Fig. 1, individual II-1) had undergone complete thyroidectomy at the age of 36 years because of recurrent hyperthyroidism and multinodular goitre. Histopathological evaluation showed multiple microfollicular adenomas in both thyroid lobes. At the age of 47 years, he currently receives $100 \mu \mathrm{g}$ L-thyroxine per day, and his thyroid function is normal. His mother had no history of thyroid disease and her thyroid hormone levels were within the normal range. The paternal grandmother (Fig. 1, individual I-1) was diagnosed with nodular goitre and hyperthyroidism in adulthood. Subtotal thyroidectomy was performed in the early 1980s when the patient was 60 years old. Histopathological evaluation revealed a follicular oncocytic thyroid carcinoma, sized $20 \times 15 \mathrm{~mm}$, in the left lobe, with capsular infiltration and angioinvasion ( $\mathrm{pT} 3 \mathrm{~N} 0 \mathrm{M} 0$; International Union Against Cancer, Geneva, Switzerland, 2002), as well as multiple microfollicular adenomas in both lobes. Subsequently, she received ablative radioiodine therapy, and her clinical follow-up was unremarkable.

\section{TSH-R germline mutation V509A}

The absence of thyroid autoantibodies, early clinical onset, and familial clustering suggested hereditary hyperthy- roidism in the index patient. We performed a genetic analysis of the TSH-R, identifying heterozygous genomic TSH-R mutation V509A in the index patient and affected family members (Fig. 1, insert). Transition of $\mathrm{T}$ (GTG) to C (GCG) in codon 509 (exon 10) results in replacement of valine by alanine (V509A) in TMH3 of the TSH-R. V509A was the first human genomic TSH-R mutation described (Duprez et al. 1994). The wild-type TSH-R sequence was found in the mother of the index patient.

\section{Molecular modelling of TSH-R V509A receptor structure and function}

To account for the activation of the V509A TSH-R at the structural level, molecular dynamic (MD) simulation and modelling studies were performed. For the wild-type TSH-R a tight 'knob-and-hole' interaction between TMH3 and TMH5 was identified for this particular receptor area with residue A593 as the counterpart of position 509 (Fig. 2). During MD simulations, the distance between the C-alpha atoms of 509A and A593 (approximately 1 Angstrom) was considerably shorter than in the wild-type TSH-R. In detail, after equilibration the distances between the C-alpha atoms of position 509 and 593 were stabilized during the trajectories for the V509A mutant in a range between 5.4 and 6.4 Angstroms and for the wild-type TSH-R in the range of $6.5-7 \cdot 7$ Angstroms. In the wild-type TSH-R the branched side chain of Val509 ('knob') in TMH3 constrains residue Ala593 (hydrophobic 'hole') in the opposite position in TMH5 (Fig. 3A). The Ala593 side chain acts as an intertwined complementary counterpart participating at a hydrophobic hole that is coated by the other hydrophobic residues Phe594, Leu539 at TMH5 and Tyr510, Thr513 at TMH3. Mutation Ala509, deleting the bulky side chain, releases the intertwining and permits the escape of Ala593 from the hydrophobic hole. Thus, the intracellular movement of TMH5 and intracellular loop 3 may lead to activation of the mutant TSH-R (Fig. 3B).

We next developed and tested an experimental double mutant V509A/A593V TSH-R model in which the 'knob' functionality is restored by valine at position 593 , with the branched side chain fixing A509 and a methyl group filling in its hydrophobic hole (Fig. 3C). MD simulation showed a similar distance between TMH3 and TMH5 for wild-type and double mutant TSH-R. In effect, the introduction of a second site mutant, A593V, is predicted to restabilize the TSH-R in its native conformation. Taken together, the modelling results suggest that in TSH-R V509A a release of tight interactions between amino acid residues V509 and A593 results in an increased mobility of TMH3 and TMH5, causing constitutive TSH-R activation. 

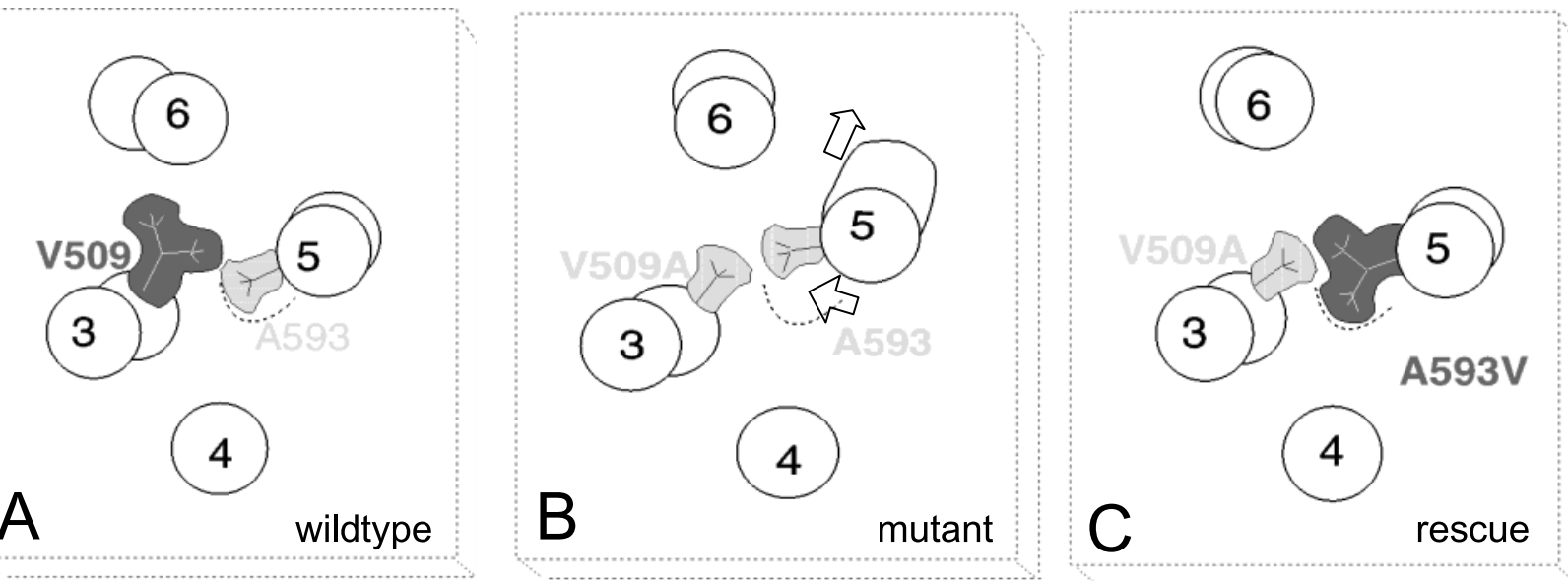

Figure 3 Functional model of interaction between TSH-R transmembrane domains TMH3 and TMH5. (A) In wild-type TSH-R, V509 ('knob') fixes the oppositely located Ala593 (TMH5) in a hydrophobic hole. (B) The small alanine side chain in mutant TSH-R V509A permits escape of Ala593, thus allowing intracellular movement of TMH5. (C) In TSH-R V509A/Ala593V, functionality of the knob is taken over by valine at position 593 as the branched side chain of Val593 fixes alanine at TMH3, and a methyl portion of V593 fills in the hydrophobic hole. In effect, the designed second site mutant A593V stabilizes the native TSH-R conformation.

In vitro TSH-R V509A activation and signal transduction

The effects of mutation V509A on basal and ligand-induced TSH-R receptor activation was studied in vitro in human embryonic HEK 293 cells expressing wild-type or mutated TSH-R (Fig. 4, insert). A significant $(2 \cdot 8$-fold $)$ increase in basal intracellular
cAMP accumulation was observed in the mutated TSH-R V509A compared with the wild-type TSH-R (Fig. 4) in the absence of TSH, indicating constitutive TSH-R activation. Incubation with different concentrations of TSH showed a similar increase in cAMP production in cells transfected with wild-type TSH-R and the TSH-R V509A, demonstrating dose-

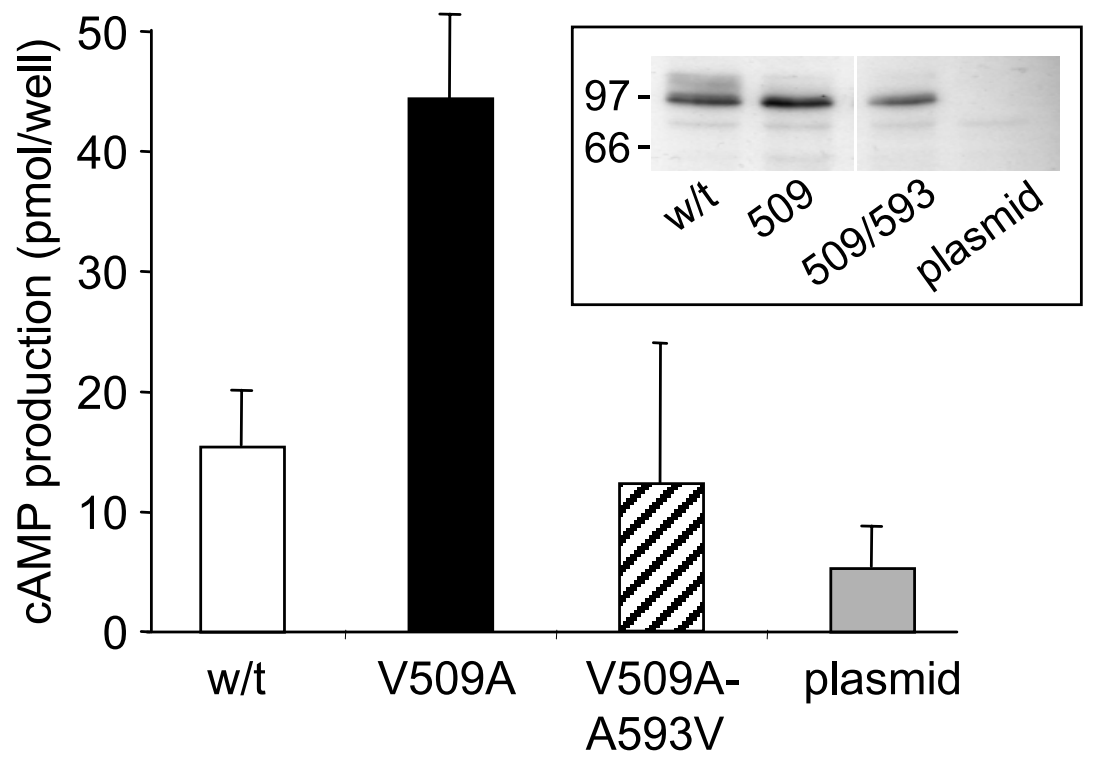

Figure 4 Basal cAMP production in HEK cells transfected with TSH-R constructs, showing 2-8-fold cAMP levels for TSH-R V509A as compared with wild-type (w/t) TSH-R. Note the reduction of cAMP production to base line levels in double mutant V509A/A593V TSH-R. Insert: expression of recombinant TSH-R in HEK 293 cells, as detected by immunoblot. Plasmid denotes control transfection with empty plasmid vector. 97 and 66 denote 97 and $66 \mathrm{kDa}$. 


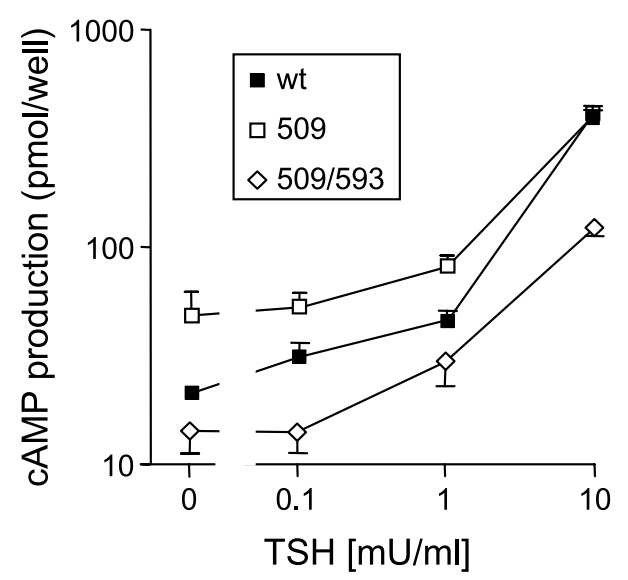

Figure 5 Dose-dependent in vitro cAMP production in the presence of TSH ligand in HEK 293 cells expressing wild-type (wt) or mutant TSH-R.

dependent ligand-induced proximal signal transduction (Fig. 5).

Functional 'rescue' of V509A mutant TSH-R by A593V

To experimentally validate the proposed concept of TSH-R V509A activation, a second site TSH-R mutation was introduced into TMH5, replacing alanine in position 593 by valine, thus generating the reciprocal double mutant V509A/A593V. Signal transduction of this double mutant TSH-R was analysed in transfected HEK 293 cells and compared with the wild-type TSH-R and the V509A TSH-R variant. V509A/A593V TSH-R was characterized by a lower basal cAMP production than V509A TSH-R, comparable with the wild-type TSH-R activity (Fig. 4) and A593V TSH-R activity (not shown). Doseresponsiveness to exogenous TSH was maintained in the double mutant V509A/A593V TSH-R (Fig. 5). Similar cell surface expression of wild-type, mutant and double mutant TSH-R was confirmed by immunofluorescence microscopy in transiently transfected HEK 293 cells, using a monoclonal antibody directed against the TSH-R extracellular domain (Fig. 6) which cannot rule out subtle quantitative differences of receptor expression. Taken together, the introduction of valine in position 593 (TMH5) reverses the constitutive activation of mutant V509A TSH-R to normal wild-type TSH-R levels.

\section{Discussion}

Congenital hyperthyroidism in this family is caused by a germline mutation of the TSH receptor, V509A. This mutation was the first activating genomic TSH-R variant ever described (Thomas et al. 1982, Duprez et al. 1994). In comparison with the initial French family, thyrotoxicosis in our index patient developed much earlier and represents the youngest symptomatic patient carrying the V509A TSH-R variant reported so far.

Patients with activating genomic TSH-R mutations are characterized by a variable clinical expression of hyperthyroidism (Corvilain et al. 2001). Disease activity in affected individuals correlates with the degree of constitutive receptor activation, as determined by basal cAMP production, thus establishing a phenotype-genotype relationship. Severe hyperthyroidism has been found in genomic TSH-R variants with excessive basal cAMP production, presenting a fourfold to sevenfold increase compared with the wild-type TSH-R (Kopp et al. 1995, de Roux et al. 1996a, Fuhrer et al. 1997, Holzapfel et al. 1997, Tonacchera et al. 2000). In contrast, in our kindred basal cAMP accumulation in the V509A TSH-R was only increased by $2 \cdot 8$-fold, similar to earlier studies using different in vitro cell systems (Duprez et al. 1994, Kosugi et al. 2000, Fuhrer et al. 2003). Likewise, thyroid nodules and goitre develop earlier in patients carrying TSH-R variants with high constitutive receptor activation (Kopp et al. 1995, de Roux et al. 1996a, Fuhrer et al. 1997, Holzapfel et al. 1997, Tonacchera et al. 2000) compared with V509A TSH-R, as described in this and previous reports (Thomas et al. 1982, Leclere et al. 1997).

Structure-function analysis of TSH-R substitutions has provided insight into the molecular mechanisms of TSH-R activation (Biebermann et al. 1998, Govaerts et al. 2001, Neumann et al. 2001, Kleinau et al. 2004, Urizar
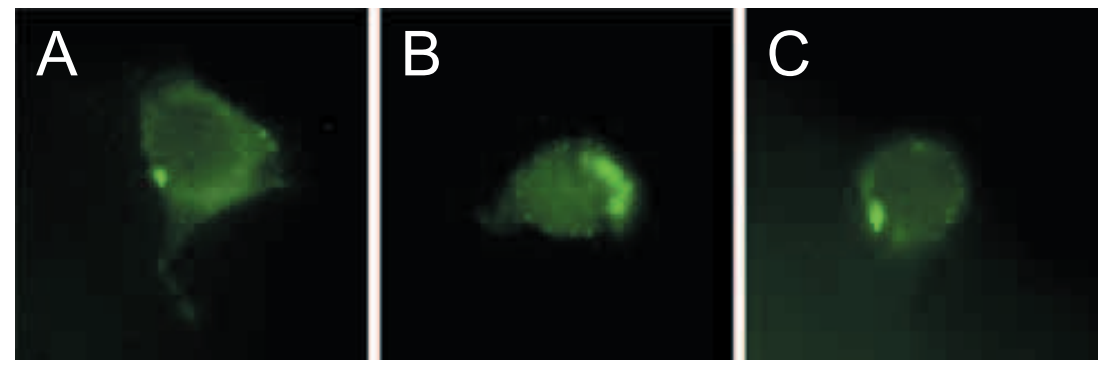

Figure 6 Cell surface expression of (A) wild-type TSH-R, (B) TSH-R V509A/A593V, and (C) TSH-R V509A, as detected by immunofluorescence after in vitro transfection of HEK 293 cells, using a monoclonal antibody directed against the TSH-R extracellular domain. 
et al. 2005). Three activating TSH-R mutations located at TMH3 have been identified to date: V509A, S505R/N, and L512R. In our molecular TSH-R model, all these TMH3 residues point into the receptor core region located between the transmembrane helices. For positions 505 and 512 it is probable that bulkier or more hydrophilic substitutions are repulsing TMH6/TMH7 from TMH3, thereby changing the TSH-R from the constrained native state to the activated state. Using a double mutant strategy it was shown that no hydrogen bond interaction exists between S508 in TMH3 and R633 in TMH3 (Neumann et al. 2001). Repulsing scenarios by the introduction of larger amino acids have been described for TMH5 and TMH6 residues of the TSH-R (Biebermann et al. 1998). However, this scenario seems unlikely for V509A observed in our family, as the alanine substitution exhibits a reduced size and (weak) hydrophobic properties.

Other mechanisms seem to be involved in the interaction between TMH3 and TMH5 in the centre of the transmembrane region. Molecular modelling of natural GPCR variants, including the gonadotrophin-releasing hormone receptor (Karges et al. 2003), has improved the understanding of the GPCR function in human disease. We therefore performed a computed modelling of the TSH-R variant V509A, suggesting that replacement of valine 509 by alanine causes a loss of the tight 'knob-andhole' interaction between V509 (TMH3) and A593 (TMH5), thereby releasing interhelical constraints to increase the mobility of TMH3 and TMH5. As signal transduction is mainly transmitted by residues in the third intracellular loop (Kosugi et al. 1994, Biebermann et al. 1998, Vlaeminck-Guillem et al. 2002), the intracellular movement of TMH5 may thus initiate stimulation of adenylate cyclase activity.

The experimental introduction of second site suppressor mutations in conjunction with molecular modelling has been used to identify intramolecular GPCR interactions in the TSH-R (Neumann et al. 2001) and vasopressin-V2 receptor (Schulein et al. 2001, Oksche et al. 2002). We generated a double mutant, V509A/A593V TSH-R, for functional rescue of V509A. The 'fixed-and-released' interaction hypothesis suggested by our modelling data was experimentally addressed by replacing alanine 593 in TMH5 by valine, leading to normalization of basal cAMP production and TSH-R activity. Our results demonstrate that specific intertwined 'knob-and-hole' patterns are stabilizing the interaction between residue V509 (TMH3) and A593 (TMH5) to maintain the TSH receptor in its native conformation, and that release of the intertwining in this particular region turns the TSH-R into an active conformation. As residues 509 and 593 are highly conserved in all glycoprotein hormone receptors (GPHRs), this activation mechanism may apply to all GPHRs.

Patients with activating genomic TSH-R mutations and persistent hyperthyroidism may have a predisposition for thyroid neoplasia, since the constitutive activation of signal transduction pathways stimulates cell proliferation and transformation (Russo et al. 1995a, Fournes et al. 1998, Ludgate et al. 1999). Constitutive activity of the TSH-R mainly increases stimulation of adenylate cyclase but rarely also affects the phospholipase C pathway (Parma et al. 1995). Activating somatic mutations of the TSH-R have been found in thyroid neoplasia (Spambalg et al. 1996, Russo et al. 1997, 1999, Mircescu et al. 2000) but until now thyroid carcinoma has not been reported in individuals carrying a genomic activating TSH-R mutation. The low prevalence for thyroid cancer in affected individuals with activating germline TSH-R mutations may be partially explained by early thyroidectomy due to thyrotoxicosis (Thomas et al. 1982, Leclere et al. 1997). In addition, malignant transformation may require additional (i.e. somatic) mutations, but genetic events involved in this process have not been identified (Russo et al. 1995a, 1997, 1999). In contrast, the occurrence of nodular transformation is a common finding in patients with activating germline TSH-R variants (Kopp et al. 1995, Tonacchera et al. 1996, Leclere et al. 1997). In the general population, the risk for thyroid cancer is increased in patients with multinodular goitre (From et al. 2000). From a clinical point of view, medical and imaging follow-up to detect thyroid neoplasia seems prudent in individuals with activating TSH-R mutations who do not undergo ablative therapy.

In summary, we propose and experimentally validate a novel mechanism of constitutive GPCR activation in TSH-R variant V509A, leading to hyperthyroidism and a predisposition to thyroid neoplasia in affected patients.

\section{Acknowledgements}

We thank Dr G Vassart, Brussels, for his friendly support and advice. We are grateful to Dr Franz Oswald and Andreas Spyrantis, Ulm, for assistance in expression studies.

\section{Funding}

This work was supported by an APE Clinical Fellowship, German Society of Endocrinology (to B K), Deutsche Forschungsgemeinschaft, GK 1041 'Molecular Endocrinology' (to W K), and Kr1273 (to G K). The authors declare that there is no conflict of interest that would prejudice the impartiality of the work reported in this manuscript.

\section{References}

Biebermann H, Schoneberg T, Schulz A, Krause G, Gruters A, Schultz G \& Gudermann T 1998 A conserved tyrosine residue (Y601) in transmembrane domain 5 of the human thyrotropin receptor serves as a molecular switch to determine $G$ protein coupling. FASEB Journal 12 1461-1471. 
Case DA, Pearlman DA, Cladwell JW, Chaetham III TE, Ross WS, Simmerling CL, Darden TA, Merz KM, Stanton RV, Cheng AL et al. 1998 AMBER 5·0. University of California, San Francisco.

Corvilain B, Van-Sande J, Dumont JE \& Vassart G 2001 Somatic and germline mutations of the TSH receptor and thyroid diseases. Clinical Endocrinology 55 143-158.

Duprez L, Parma J, Van-Sande J, Allgeier A, Leclere J, Schvartz C, Delisle MJ, Decoulx M, Orgiazzi J, Dumont J et al. 1994 Germline mutations in the thyrotropin receptor gene cause non-autoimmune autosomal dominant hyperthyroidism. Nature Genetics 7 396-401.

Fournes B, Monier R, Michiels F, Milgrom E, Misrahi M \& Feunteun J 1998 Oncogenic potential of a mutant human thyrotropin receptor expressed in FRTL-5 cells. Oncogene 16 985-990.

From G, Mellemgaard A, Knudsen N, Jorgensen T \& Perrild H 2000 Review of thyroid cancer cases among patients with previous benign thyroid disorders. Thyroid 10 697-700.

Fuhrer D, Wonerow P, Willgerodt H \& Paschke R 1997 Identification of a new thyrotropin receptor germline mutation (Leu629 Phe) in a family with neonatal onset of autosomal dominant nonautoimmune hyperthyroidism. Journal of Clinical Endocrinology and Metabolism 82 4234-4238.

Fuhrer D, Lewis MD, Alkhafaji F, Starkey K, Paschke R, Wynford-Thomas D, Eggo M \& Ludgate M 2003 Biological activity of activating thyroid-stimulating hormone receptor mutants depends on the cellular context. Endocrinology 144 4018-4030.

Gether U 2000 Uncovering molecular mechanisms involved in activation of $\mathrm{G}$ protein-coupled receptors. Endocrine Reviews $\mathbf{2 1}$ 90-113.

Govaerts C, Lefort A, Costagliola S, Wodak SJ, Ballesteros JA, Van-Sande J, Pardo L \& Vassart G 2001 A conserved Asn in transmembrane helix 7 is an on/off switch in the activation of the thyrotropin receptor. Journal of Biological Chemistry 276 22991-22999.

Holzapfel HP, Wonerow P, von-Petrykowski W, Henschen M, Scherbaum WA \& Paschke R 1997 Sporadic congenital hyperthyroidism due to a spontaneous germline mutation in the thyrotropin receptor gene. Journal of Clinical Endocrinology and Metabolism 82 3879-3884.

Karges B, Karges W, Mine M, Ludwig L, Kuhne R, Milgrom E \& de Roux N 2003 Mutation Ala(171)Thr stabilizes the gonadotropinreleasing hormone receptor in its inactive conformation, causing familial hypogonadotropic hypogonadism. Journal of Clinical Endocrinology and Metabolism 88 1873-1879.

Kleinau G, Jaschke H, Neumann S, Lattig J, Paschke R \& Krause G 2004 Identification of a novel epitope in the thyroid-stimulating hormone receptor ectodomain acting as intramolecular signaling interface. Journal of Biological Chemistry 279 51590-51600.

Kopp P, van-Sande J, Parma J, Duprez L, Gerber H, Joss E, Jameson JL, Dumont JE \& Vassart G 1995 Brief report: congenital hyperthyroidism caused by a mutation in the thyrotropin-receptor gene. New England Journal of Medicine 332 150-154.

Kosugi S, Shenker A \& Mori T 1994 Constitutive activation of cyclic AMP but not phosphatidylinositol signaling caused by four mutations in the 6th transmembrane helix of the human thyrotropin receptor. FEBS Letters 356 291-294.

Kosugi S, Hai N, Okamoto H, Sugawa H \& Mori T 2000 A novel activating mutation in the thyrotropin receptor gene in an autonomously functioning thyroid nodule developed by a Japanese patient. European Journal of Endocrinology 143 471-477.

Leclere J, Bene MC, Aubert V, Klein M, Pascal-Vigneron V, Weryha G \& Faure G 1997 Clinical consequences of activating germline mutations of TSH receptor, the concept of toxic hyperplasia. Hormone Research 47 158-162.

Liesenkotter KP, Kiebler A, Stach B, Willgerodt H \& Gruters A 1997 Small thyroid volumes and normal iodine excretion in Berlin schoolchildren indicate full normalization of iodine supply.
Experimental and Clinical Endocrinology and Diabetes 105 (Suppl 4) $46-50$.

Ludgate M, Gire V, Crisp M, Ajjan R, Weetman A, Ivan M \& Wynford-Thomas D 1999 Contrasting effects of activating mutations of $\mathrm{G}$ alpha $\mathrm{S}$ and the thyrotropin receptor on proliferation and differentiation of thyroid follicular cells. Oncogene 18 4798-4807.

Mircescu H, Parma J, Huot C, Deal C, Oligny LL, Vassart G \& Van-Vliet G 2000 Hyperfunctioning malignant thyroid nodule in an 11-year-old girl: pathologic and molecular studies. Journal of Pediatrics 137 585-587.

Neumann S, Krause G, Chey S \& Paschke R 2001 A free carboxylate oxygen in the side chain of position 674 in transmembrane domain 7 is necessary for TSH receptor activation. Molecular Endocrinology 15 1294-1305.

Oksche A, Leder G, Valet S, Platzer M, Hasse K, Geist S, Krause G, Rosenthal A \& Rosenthal W 2002 Variant amino acids in the extracellular loops of murine and human vasopressin V2 receptors account for differences in cell surface expression and ligand affinity. Molecular Endocrinology 16 799-813.

Palczewski K, Kumasaka T, Hori T, Behnke CA, Motoshima H, Fox BA, Le-Trong I, Teller DC, Okada T, Stenkamp RE et al. 2000 Crystal structure of rhodopsin: a G protein-coupled receptor. Science $289739-745$.

Parma J, Duprez L, Van-Sande J, Cochaux P, Gervy C, Mockel J, Dumont J \& Vassart G 1993 Somatic mutations in the thyrotropin receptor gene cause hyperfunctioning thyroid adenomas. Nature 365 649-651.

Parma J, Van-Sande J, Swillens S, Tonacchera M, Dumont J \& Vassart G 1995 Somatic mutations causing constitutive activity of the thyrotropin receptor are the major cause of hyperfunctioning thyroid adenomas: identification of additional mutations activating both the cyclic adenosine $3^{\prime}, 5^{\prime}$-monophosphate and inositol phosphate-Ca ${ }^{2+}$ cascades. Molecular Endocrinology 9 725-733.

Parnot C, Miserey-Lenkei S, Bardin S, Corvol P \& Clauser E 2002 Lessons from constitutively active mutants of $\mathrm{G}$ protein-coupled receptors. Trends in Endocrinology and Metabolism 13 336-343.

Prader A, Largo RH, Molinari L \& Issler C 1989 Physical growth of Swiss children from birth to 20 years of age. First Zurich longitudinal study of growth and development. Helvetica Paediatrica Acta Supplementum 52 1-125.

de Roux N, Polak M, Couet J, Leger J, Czernichow P, Milgrom E \& Misrahi M 1996a A neomutation of the thyroid-stimulating hormone receptor in a severe neonatal hyperthyroidism. Journal of Clinical Endocrinology and Metabolism 81 2023-2026.

de Roux N, Misrahi M, Brauner R, Houang M, Carel JC, Granier M, Le-Bouc Y, Ghinea N, Boumedienne A, Toublanc JE et al. $1996 b$ Four families with loss of function mutations of the thyrotropin receptor. Journal of Clinical Endocrinology and Metabolism $814229-4235$.

Russo D, Arturi F, Schlumberger M, Caillou B, Monier R, Filetti S \& Suarez HG 1995a Activating mutations of the TSH receptor in differentiated thyroid carcinomas. Oncogene 11 1907-1911.

Russo D, Arturi F, Wicker R, Chazenbalk GD, Schlumberger M, DuVillard JA, Caillou B, Monier R, Rapoport B, Filetti S et al. $1995 b$ Genetic alterations in thyroid hyperfunctioning adenomas. Journal of Clinical Endocrinology and Metabolism 80 1347-1351.

Russo D, Tumino S, Arturi F, Vigneri P, Grasso G, Pontecorvi A, Filetti S \& Belfiore A 1997 Detection of an activating mutation of the thyrotropin receptor in a case of an autonomously hyperfunctioning thyroid insular carcinoma. Journal of Clinical Endocrinology and Metabolism 82 735-738.

Russo D, Wong MG, Costante G, Chiefari E, Treseler PA, Arturi F, Filetti S \& Clark OH 1999 A Val 677 activating mutation of the thyrotropin receptor in a Hurthle cell thyroid carcinoma associated with thyrotoxicosis. Thyroid 9 13-17.

Schoneberg T, Schultz G \& Gudermann T 1999 Structural basis of G protein-coupled receptor function. Molecular and Cellular Endocrinology 151 181-193. 
Schulein R, Zuhlke K, Krause G \& Rosenthal W 2001 Functional rescue of the nephrogenic diabetes insipidus-causing vasopressin V2 receptor mutants $\mathrm{G} 185 \mathrm{C}$ and $\mathrm{R} 202 \mathrm{C}$ by a second site suppressor mutation. Journal of Biological Chemistry 276 8384-8392.

Schulz A, Bruns K, Henklein P, Krause G, Schubert M, Gudermann T, Wray V, Schultz G \& Schoneberg T 2000 Requirement of specific intrahelical interactions for stabilizing the inactive conformation of glycoprotein hormone receptors. Journal of Biological Chemistry 275 37860-37869.

Spambalg D, Sharifi N, Elisei R, Gross JL, Medeiros-Neto G \& Fagin JA 1996 Structural studies of the thyrotropin receptor and Gs alpha in human thyroid cancers: low prevalence of mutations predicts infrequent involvement in malignant transformation. Journal of Clinical Endocrinology and Metabolism 81 3898-3901.

Thomas JS, Leclere J, Hartemann P, Duheille J, Orgiazzi J, Petersen M, Janot C \& Guedenet JC 1982 Familial hyperthyroidism without evidence of autoimmunity. Acta Endocrinologica 100 512-518.

Tonacchera M, Van-Sande J, Cetani F, Swillens S, Schvartz C, Winiszewski P, Portmann L, Dumont JE, Vassart G \& Parma J 1996 Functional characteristics of three new germline mutations of the thyrotropin receptor gene causing autosomal dominant toxic thyroid hyperplasia. Journal of Clinical Endocrinology and Metabolism 81 547-554.

Tonacchera M, Agretti P, Rosellini V, Ceccarini G, Perri A, Zampolli M, Longhi R, Larizza D, Pinchera A, Vitti P et al. 2000 Sporadic nonautoimmune congenital hyperthyroidism due to a strong activating mutation of the thyrotropin receptor gene. Thyroid $\mathbf{1 0}$ 859-863.

Urizar E, Claeysen S, Deupi X, Govaerts C, Costagliola S, Vassart G \& Pardo L 2005 An activation switch in the rhodopsin family of G protein-coupled receptors: the thyrotropin receptor. Journal of Biological Chemistry 280 17135-17141.

Vlaeminck-Guillem V, Ho SC, Rodien P, Vassart G \& Costagliola S 2002 Activation of the cAMP pathway by the TSH receptor involves switching of the ectodomain from a tethered inverse agonist to an agonist. Molecular Endocrinology 16 736-746.

Received 1 March 2005

Accepted 9 June 2005 